http://jmscr.igmpublication.org/home/ ISSN (e)-2347-176x ISSN (p) 2455-0450

crossref DOI: https://dx.doi.org/10.18535/jmscr/v7i12.99

Journal Of Medical Science And Clinical Research

\title{
Breakfast Skipping Pattern and its associated factors among adolescents
}

\author{
Authors \\ Dr Achla Jain ${ }^{1}$, Dr Neera Mrathe ${ }^{2}$, Dr Prayank Jain ${ }^{2 *}$, Dr Anvita Mishra ${ }^{3}$ \\ Dr Anjana Niranjan ${ }^{3}$ \\ ${ }^{1}$ Third year Post graduate student, Department of Community medicine, SSMC Rewa \\ *Corresponding Author \\ Dr Prayank Jain, DM Cardiology
}

\begin{abstract}
Background: Skipping breakfast is emerging as one of the more common unhealthy dietary practices among adolescents. The development of these unhealthy eating habits during adolescence is leading hazardous health consequences and likely to continue into adulthood.

Objective: This study aimed to estimate the overall prevalence of skipping breakfast among adolescents of Rewa city M.P.

Materials and Methods: This was a cross sectional community based study, conducted among 423 adolescents of 10-19 year age group, who fulfilled the inclusion criteria. Multistage random sampling was adopted. The study was based on a modified questionnaire and standardized anthropometric measures were taken for collecting desired sample size.

Results: Out of 423 subjects pooled prevalence of skipping the breakfast was higher among the females as compared to males. Increasing trend shows with increasing age and education level. Subjects living with nuclear family and those stay away from the family had higher prevalence of skipping breakfast.

Conclusion: Skipping breakfast is more prevalent among the girls. Interventions are required to promote breakfast consumption adolescents population.

Keywords: Skipping breakfast, adolescents.
\end{abstract}

\section{Introduction}

The term 'breakfast' in English refers to "to break a fast", which breaks the overnight fast that can be as long as 12 to 16 hours, from dinner of the previous night to the next morning. Breakfast should supply one-fourth of the daily requirement of energy. ${ }^{1}$ Breakfast is the first meal of a day.

Breakfast is the most important meal of the day, because kick starts our metabolism, Recharge the body, begins burning calories starting in the morning, it helps recharge the body and brain.
Nutrients missed by skipping breakfast cannot be compensated for in other meals. Regular consumption of breakfast may have a multitude of health benefits for adolescents including increased intake of essential nutrients, improved academic performance, improved behaviour, increased satiety, decreased hunger and decreased food intake. ${ }^{2}$ Observational studies showed that regular breakfast consumption leads to a higher quality diet with increased amounts of fibre, calcium, vitamin $\mathrm{A}$, vitamin $\mathrm{C}$, riboflavin, zinc, and iron as well as decreased intake of calories, fat and 
cholesterol compared to skipping breakfast. Incorporating the breakfast meal could also lead to improvements in blood lipid and insulin profiles if the meal is of high quality. ${ }^{2,3}$ Eating a morning meal provides the brain with the necessary energy to perform cognitively and increase learning.

More specifically, breakfast enhances tasks involving processing of a complex visual display, spatial memory, short-term memory, and auditory attention. ${ }^{2}$ Research examining the impact of school breakfast programs on cognitive function found that eating breakfast led to beneficial effects in children's behaviour and learning. When breakfast was provided at school, children demonstrated lower absence and tardiness rates, fewer other disciplinary conflicts and greater attention and energy to learn. ${ }^{4}$ Although breakfast is supposed to be the most important meal of the day, it is the one that is most neglected. Skipping breakfast is one of the more common dietary practices among adolescents. The main reasons for skipping breakfast seem to be related to: Lack of time, lack of morning appetite, and for adolescents, concern about their body weight. ${ }^{5}$

Skipping breakfast is suggested to impair cognitive performance, due to the continuation of the overnight fasting condition when the morning meal is not consumed. ${ }^{6}$ Morning meal boosts memory, Many studies indicates that skipping breakfast increased hunger which subsequently led to declines in attention and memory, impairing children to learn throughout the day, students who are given a low-glycemic breakfast are able to sustain attention longer than those given a highglycemic breakfast. $^{7}$ Specifically, breakfast skippers faced problem to recall information, reduction in problem solving abilities, commit more errors on routine work. ${ }^{8}$ Another study showed that students who participate in school breakfast programs have significantly higher math scores as compare to those who skip or rarely eat breakfast. ${ }^{9}$

Adolescents who eat breakfast think faster and clearer, solve problems more easily and are more efficiently. They are less irritable and aggressive, get tired less easily and interested in games and sports. While adolescents who skip breakfast feel tired, have less energy and slower reactions. They are unable to concentrate and think quickly and may suffer from stomachaches, headaches and feel grouchy. ${ }^{10}$

Many researches has shown that children who miss breakfast showed more behavioural, emotional and academic problems as compared to those who consistently eat breakfast. ${ }^{10}$

Breakfast skipping has also been associated with other negative behaviours involving reduced academic performance increased substance abuse, and various emotional problems. ${ }^{6}$ Thus, encouraging breakfast consumption may be an important step toward improving overall health and well-being.

So Breakfast is one of the most integral components of an individual's diet and plays an important role in ensuring the good health and wellbeing of an individual. Despite the proven importance of this meal, it has been observed that it is often underrated and skipped, especially among the adolescents. Breakfast skipping is highly prevalent in many countries including the United States and Europe (10-30\%), depending on the age group, reportedly being a more common occurrence in the children and adolescents and prevalence is increasing also among adolescents of developing countries too. ${ }^{11}$

The current study was conducted among adolescents of Rewa city to assess the prevalence of skipping breakfast and its associated factors and to change breakfast consumption habits to ensure enough energy and nutrient intake in the morning among adolescents of Rewa city.

\section{Material and Methods}

After approval of institutional ethical committee, this cross sectional community based study was conducted among adolescents 10-18 yr age group in Rewa city from January to December 2018. Primarily the study was carried out to find out prevalence of obesity among adolescents with breakfast consumption pattern was taken as its 
associated factor. The Sample size was determined by taking $19.3 \%$ combined prevalence of overweight and obesity among adolescents by a systematic review of $\mathrm{H}$. Ranjani ${ }^{12}$ with relative precision $20 \%$ at $95 \%$ confidence interval. Sample size estimated was 418 .

A multistage random sampling procedure was adopted for the selection of study subjects. After obtaining ward list randomly nine wards were selected.46/47 subjects of 10 to 19 years age group were selected randomly from each ward. Thus 423 subjects who gave informed consent were included in the study and were assured of confidentiality and anonymity.

\section{Definition: Potential Dietary Strategies-} Incorporation of Breakfast: Breakfast can be defined as the first eating occasion of the day. This meal is usually consumed before 10:00 am and typically consists of 500 calories, making up $20 \%-35 \%$ of total daily energy needs. ${ }^{13}$ Data was collected by researcher using semi-structured questionnaire consisting of information about demographic data, information about breakfast consumption pattern.

Table 1: Sociodemographic characteristics of Study Subjects

\begin{tabular}{|l|c|c|}
\hline Sociodemographic characteristics & No(n= 423) & Percentage \\
\hline Gender & 242 & \\
\hline Male & 181 & 57.2 \\
\hline Female & & \\
\hline Age & 136 & 32.8 \\
\hline $10-15$ years & 287 & 67.8 \\
\hline $16-19$ years & & \\
\hline Education attained & 53 & 12.5 \\
\hline Illiterate and primary School completed & 85 & 20.1 \\
\hline $6^{\text {th }}$ to ${ }^{\text {th }}$ class & 201 & 49.4 \\
\hline $9^{\text {th }}$ to $12^{\text {th }}$ class & 76 & 18.0 \\
\hline Pursuing Graduation & & \\
\hline Type of Family & 234 & 55.3 \\
\hline Joint & 189 & 44.7 \\
\hline Nuclear & & \\
\hline Residence & 365 & 86.3 \\
\hline Staying with family & 58 & 13.7 \\
\hline Far away with family/ Hostel/ With friends & &
\end{tabular}

Association of breakfast skipping pattern with sociodemographic variable were shown in Table 2.Among males $8.3 \%$ had breakfast $<1$ times/weeks, $12.8 \% \quad 2-3 \quad$ times/week,16.1\%4-5 times / weeks, while only $62.8 \%$ had 6-7 times
Breakfast frequency was assessed with the question, "During the past week, how many days did you eat breakfast?" Responses included <1 time, 2-3 time, 4-5 times, 6-7 times in a week. Seriously ill subjects and those didn't give consent were excluded from study.

Data was entered in Microsoft Excel spread sheet, analysed and interpreted using Descriptive statistics. Chi square test of significance was used to find out the association between breakfast consumption pattern and sociodemographic variables at $\mathrm{P}$ value $<.05$ was considered significance

\section{Result and Discussion}

Table 1 shows Sociodemographic characteristics of Study Subjects. Among 423 study subjects 181(42.8\%) were females and $242(57.2 \%)$ were males. The majority of study subjects were in the age group of $16-19$ years. Around two third of the study subjects have attained middle school education and studying in higher classes and colleges.55.3\% subjects were having joint family, while most of subjects $86.3 \%$ were staying with their family. breakfast consumption. Among females 17.7\% had breakfast $<1$ times/weeks,24.3\% 2-3 times/week, 20.9\%4-5 times / weeks, while only $37.0 \%$ had 6-7 times breakfast consumption. Prevalence of skipping the breakfast was 
significantly higher among the females as compared to males ( $\mathrm{P}$ value $<0.00001$ ). Among 10-15 year age group $9.6 \%$ had breakfast $<1$ times/weeks, $13.2 \% \quad 2-3$ times/week,13.2\%4-5 times / weeks, while only $63.9 \%$ had 6-7 times breakfast consumption. Among 16-19 year age group $13.6 \%$ had breakfast <1 times/weeks, $19.8 \%$ 2-3 times/week,76.6\%4-5 times / weeks, while only $45.9 \%$ had 6-7 times breakfast consumption.
Prevalence of skipping the breakfast significantly increased with respect to increasing age ( $\mathrm{P}$ value 0.018).Significant trend of skipping breakfast were found with higher education of subjects ( $\mathrm{P}$ value $<0.00001)$ and the subjects who were staying away from family ,had highly significant association with prevalence of skipping breakfast. (P value <0.00001).

Table 2: Association of breakfast skipping pattern with sociodemographic variable

\begin{tabular}{|c|c|c|c|c|c|c|c|}
\hline \multirow[t]{2}{*}{$\begin{array}{l}\text { Socio-demographic } \\
\text { variable }\end{array}$} & \multicolumn{4}{|c|}{$\begin{array}{l}\text { Frequency of breakfast consumption per } \\
\text { week }\end{array}$} & \multirow[t]{2}{*}{$\begin{array}{c}\text { Total } \\
(\%)\end{array}$} & \multirow[t]{2}{*}{$\chi^{2}$} & \multirow[t]{2}{*}{ P value } \\
\hline & $\begin{array}{c}<1 \\
\text { times/ } \\
\text { weeks } \\
(\%) \\
\end{array}$ & $\begin{array}{c}2-3 \\
\text { times/we } \\
\text { ek } \\
(\%) \\
\end{array}$ & $\begin{array}{c}\text { 4-5 times } \\
\text { / weeks } \\
(\%)\end{array}$ & $\begin{array}{c}\text { 6-7 times } \\
\text { /weeks } \\
(\%)\end{array}$ & & & \\
\hline \multicolumn{8}{|l|}{ Gender } \\
\hline Male & $\begin{array}{c}20 \\
(8.3)\end{array}$ & $\begin{array}{c}31 \\
(12.8)\end{array}$ & $\begin{array}{c}39 \\
(16.1)\end{array}$ & $\begin{array}{c}152 \\
(62.8)\end{array}$ & 242 & \multirow[t]{2}{*}{29.85} & \multirow[t]{2}{*}{$\begin{array}{c}<0.0000 \\
1\end{array}$} \\
\hline Female & $\begin{array}{c}32 \\
(17.7)\end{array}$ & $\begin{array}{c}44 \\
(24.3)\end{array}$ & $\begin{array}{c}38 \\
(20.9)\end{array}$ & $\begin{array}{c}67 \\
(37.0)\end{array}$ & 181 & & \\
\hline \multicolumn{8}{|l|}{ Age } \\
\hline $10-15$ years & $\begin{array}{c}13 \\
(9.6)\end{array}$ & $\begin{array}{c}18 \\
(13.2)\end{array}$ & $\begin{array}{c}18 \\
(13.2)\end{array}$ & $\begin{array}{c}87 \\
(63.9)\end{array}$ & 136 & \multirow[t]{2}{*}{10.06} & \multirow[t]{2}{*}{0.018} \\
\hline 16-19 years & $\begin{array}{c}39 \\
(13.6)\end{array}$ & $\begin{array}{c}57 \\
(19.8)\end{array}$ & $\begin{array}{c}59 \\
(76.6)\end{array}$ & $\begin{array}{c}132 \\
(45.9)\end{array}$ & 287 & & \\
\hline \multicolumn{8}{|l|}{ Education attained } \\
\hline $\begin{array}{l}\text { Illiterate and primary Scho } \\
\text { ol completed }\end{array}$ & $\begin{array}{c}3 \\
(5.7)\end{array}$ & $\begin{array}{c}5 \\
(9.4)\end{array}$ & $\begin{array}{c}7 \\
(13.2)\end{array}$ & $\begin{array}{c}38 \\
(71.7)\end{array}$ & 53 & \multirow[t]{4}{*}{89.78} & \multirow[t]{4}{*}{$\begin{array}{c}<0.0000 \\
1\end{array}$} \\
\hline $6^{\text {th }}$ to $8^{\text {th }}$ class & $\begin{array}{c}6 \\
(7.1)\end{array}$ & $\begin{array}{c}10 \\
(11.8)\end{array}$ & $\begin{array}{c}13 \\
(15.3)\end{array}$ & $\begin{array}{c}56 \\
(65.9)\end{array}$ & 85 & & \\
\hline $9^{\text {th }}$ to $12^{\text {th }}$ class & $\begin{array}{c}19 \\
(9.5)\end{array}$ & $\begin{array}{c}31 \\
(15.4) \\
\end{array}$ & $\begin{array}{c}40 \\
(19.9) \\
\end{array}$ & $\begin{array}{c}119 \\
(56.9) \\
\end{array}$ & 209 & & \\
\hline Pursuing Graduation & $\begin{array}{c}24 \\
(31.6) \\
\end{array}$ & $\begin{array}{c}29 \\
(38.2) \\
\end{array}$ & $\begin{array}{c}17 \\
(22.4) \\
\end{array}$ & $\begin{array}{c}6 \\
(7.8)\end{array}$ & 76 & & \\
\hline \multicolumn{8}{|l|}{ Type of Family } \\
\hline Joint & $\begin{array}{c}23 \\
(9.8)\end{array}$ & $\begin{array}{c}25 \\
(10.7)\end{array}$ & $\begin{array}{c}38 \\
(16.2)\end{array}$ & $\begin{array}{c}148 \\
(63.2)\end{array}$ & 234 & \multirow[t]{2}{*}{31.68} & \multirow[t]{2}{*}{$\begin{array}{c}<0.0000 \\
1\end{array}$} \\
\hline Nuclear & $\begin{array}{c}29 \\
(15.8)\end{array}$ & $\begin{array}{c}50 \\
(26.4) \\
\end{array}$ & $\begin{array}{c}39 \\
(20.6) \\
\end{array}$ & $\begin{array}{c}71 \\
(37.6)\end{array}$ & 189 & & \\
\hline \multicolumn{8}{|l|}{ Residence } \\
\hline Staying with family & $\begin{array}{c}33 \\
(9.0)\end{array}$ & $\begin{array}{c}48 \\
(13.2)\end{array}$ & $\begin{array}{c}69 \\
(32.1) \\
\end{array}$ & $\begin{array}{c}215 \\
(58.9)\end{array}$ & 365 & \multirow[t]{2}{*}{81.25} & \multirow[t]{2}{*}{$\begin{array}{c}<0.0000 \\
1\end{array}$} \\
\hline $\begin{array}{l}\text { Far away with family/ Hos } \\
\text { tel/ With friends }\end{array}$ & $\begin{array}{c}19 \\
(32.7)\end{array}$ & $\begin{array}{c}27 \\
(46.6)\end{array}$ & $\begin{array}{c}8 \\
(13.8)\end{array}$ & $\begin{array}{c}4 \\
(6.9)\end{array}$ & 58 & & \\
\hline
\end{tabular}

\section{Discussion}

These studies assess the prevalence of skipping breakfast and its associated factors among adolescents 10-18 year age group of Rewa city, M.P., India. An important finding was that more than half of these subjects in Rewa city did not consume breakfast daily. In this study, non-daily consumption of breakfast was far greater among subjects staying away from family.

Raksha Goyal et $\mathbf{a l}^{14}$ in their study also found more than half $(70.9 \%)$ prevalence of Breakfast skipping. Monika Arora et al ${ }^{15}$ in their study explored the patterns of breakfast consumption among 8th and 10th grade students in Delhi, India 
found that $30 \%$ of the total participants consumed breakfast less than daily and age and education were significantly associated with breakfast consumption. A although in their study they found significantly lower prevalence of breakfast skipping pattern among older students as compared to younger students (Chi-square statistic=12.09; $\mathrm{P}=0.027$ ), and higher among 8th graders than 10th graders (Chi-square statistic=7.97; The prevalence was higher among subjects with higher SES, which was in concordance with our study the difference may be due to different sociodemographic variables. Atul Watharkar et al $^{16}$ In their study found $47.3 \%$ prevalence of skipping breakfast among students of age group 12-15 years in four schools of Kanpur, U.P. Chitra $\mathbf{U}$ et al $^{\mathbf{1 7}}$ who carried out their study among urban schoolchildren found that Only $42.8 \%$ of the children ate breakfast regularly. Over half of the children skipped breakfast, ranging from daily to once in two weeks.

Skipping breakfast is more prevalent among the girls in our study, Chitra $\mathbf{U}$ et $\mathbf{a l}^{\mathbf{1 7}}$ in their study also suggest that regular breakfast consumption is more common among girls in India. Though $\mathbf{M}$. arora et al ${ }^{15}$ did not find significant differences in the frequency of breakfast consumption between boys and girls, while Croezen $S$ et $\mathbf{a l}^{\mathbf{1 8}}$ and Rampersaud GC $^{\mathbf{1 9}}$ et al in their study found higher prevalence among boys in the developed countries.

Increasing trend of skipping breakfast shows with increasing age and education level. Older students were found to skip breakfast more often in our study. arora et al $^{15}$ also found higher prevalence among older age groups and 10th graders as compared to younger age groups and $8^{\text {th }}$ grades ,These findings are consistent with prior literature from developed countries from Croezen $\mathbf{S}$ et $\mathbf{a l}^{\mathbf{1 8}}$ and Rampersaud $\mathbf{G C}^{\mathbf{1 9}}$ that suggests breakfast skipping increases with age.

\section{Conclusion and Recommendation}

Skipping breakfast is more prevalent among the girls. Increasing trend shows with increasing age and education level. Subjects living with nuclear family and those stay away from the family had higher prevalence of skipping breakfast.

More emphasis should be placed on breakfast habits, especially among adolescents because it's a time when behavioural patterns are developing and stabilizing.

There is scope for improvement, as most of the subjects in the present study did not eat breakfast daily. Schools or college have to organize some programs that can include promoting a healthy breakfast (eg, whole grain cereals, low-fat milk, and fresh fruit diets including nutrient- and fibrerich carbohydrates). There should be provision of a short break in the morning, to allow students to consume breakfast. Encourage adolescents to eat breakfast that they carry from home. Many schools start very early in the morning, leaving no time for students to have a wholesome breakfast which is an important barrier to overcome. A supportive social environment to influence parents and peers has to build to promote breakfast consumption.

Funding: No funding sources

Conflict of interest: No

\section{References}

1. Anderson, Heather Arndt (2013). Breakfast: A History. AltaMira Press. ISBN 0759121656

2. Breakfast for learning, in Child Nutrition Fact Sheet, F.R.A. Center, Editor. 2008, www.frac.org: Washington, DC. p. 1-5

3. Farshchi, H., Regular meal frequency creates more appropriate insulin sensitivity and lipid profiles compared with irregular meal frequency in healthy lean women. European journal of clinical nutrition, 2004. 58(7): p. 1071-7.

4. Murphy, J., The relationship of school breakfast to psychosocial and academic functioning: cross-sectional and 
longitudinal observations in an inner-city school sample. Archives of pediatrics \& adolescent medicine, 1998. 152(9): p. 899907

5. Affinita A, Catalani L, Cecchetto G, De Lorenzo G, Dilillo D, DoneganiG, et al. Breakfast: A multidisciplinary approach. Ital J Pediatr 2013;39:44]

6. Gajre, N., Breakfast eating habit and its influence on attention-concentration, immediate memory and school concentration. . Indian Pediatrics, 2008. 45(10): p. 824-8.

7. Pollitt, E., Breakfast and cognition: an integrative summary. American Journal of Clinical Nutrition, 1998. 67(4): p. 804S813S.

8. Gajre, Wesnes, K.A., et al., Breakfast reduces declines in attention and memory over the morning in schoolchildren. Appetite, 2003. 41(3): p. 329-31

9. Breakfast for Health ,Archives of Pediatric and Adolescent Medicine, 157(8), 780784.]

10. Kleinman, R., Hunger in Children in the United States: Potential Behavioral and Emotional Correlates. Pediatrics, 1998. 101(1): p. E3

11. Rampersaud GC, Pereira MA, Girard BL, Adams J, Metzl JD. Breakfast habits, nutritional status, body weight, and academic performance in children and adolescents. J Am Diet Assoc 2005;105:743-60. ${ }^{\text {] }}$

12. Ranjani H, Mehreen T S, Pradeepa R, Anjana RM, Garg R, Anand K, Mohan V. Epidemiology of childhood overweight \& obesity in India: A systematic review. Indian J Med Res 2016;143:160-74.

13. Timlin, M., Breakfast Eating and Weight Change in a 5-Year Prospective Analysis of Adolescents: Project EAT (Eating
Among Teens). Pediatrics, 2008. 121(3): p. e638-45.].

14. Goyal R, Julka S. Impact of breakfast skipping on the health status of the population. Indian $\mathbf{J}$ Endocr Metab 2014;18:683-7

15. Arora et al.: Association of breakfast intake with obesity, dietary and physical activity behavior among urban schoolaged adolescents in Delhi, India: results of a cross-sectional study. BMC Public Health 2012 12:881

16. Watharkar A, Nigam S, Martolia DS, Varma P, Barman SK, Sharma RP. Assessment of risk factors for overweight and obesity among school going children in Kanpur, Uttar Pradesh. Indian J Comm Health. 2015; 27, 2: $216-222$.

17. Chitra U, Reddy CR: The role of breakfast in nutrient intake of urban school children. Public Health Nutr 2007, 10:55-58.

18. Croezen S Visscher TL, Ter Bogt NC, Veling ML, Haveman-Nies A: Skipping breakfast, alcohol consumption and physical inactivity as risk factors for overweight and obesity in adolescents: results of the E-MOVO project. Eur J Clin Nutr 2009, 63:405-412

19. Rampersaud GC, Pereira MA, Girard BL, Adams J, Metzl JD: Breakfast habits,nutritional status, body weight, and academic performance in children and adolescents. J Am Diet Assoc 2005, 105:743-760. 